\title{
Universities, Associations, and Internationalization: Powerful Forces for Our Time
}

\author{
Laura E. Rumbley
}

International. Association. Universities. It is hard for me to imagine three words that more meaningfully capture the forces that have animated my professional life over the last quarter century. As an international education specialist, a researcher focused on higher education institutions and systems around the world, and as someone who has worked for two European-level higher education associations, the power and potential of universities, working in tandem through the mechanisms of associations, and engaging internationally to advance their collective interests and agendas, resonates with me very clearly and very personally.

Beyond my own personal connection with these dynamics, however, I also perceive these synergies having a great deal of potential to effect positive change in the world over the next twenty-five years and more, as we look toward a future of immense complexity and challenge. Indeed, the international higher education community and its core organizations, such as the International Association of Universities (IAU), are well-positioned to play a vital role in our collective future, but they must be effectively supported to do so. If this happens, the association sector can continue, and expand upon, its crucial work to help frame the issues - social, economic, environmental - that will demand our attention around the world in the coming years. Universities can further develop their capacity to act as incubators for the kind of creative and courageous thinking that will be necessary to address the massive challenges we face locally and globally. And high-quality, critically assessed educational experiences that are imbued purposefully with international and intercultural dimensions, as well as social justice sensitivities can inspire and empower a new generation of creative, committed, and principled individuals who will carry forward our aspirations for the future.

\footnotetext{
L. E. Rumbley (凶)

European Association for International Education, Amsterdam, The Netherlands e-mail: rumbley@eaie.org 
Of course, all of these mechanisms must act in tandem to deliver their full potential, which requires sustained commitment as well as awareness of both the pitfalls and possibilities embedded in our circumstances. The key is to imagine the future we desire, sketch out a roadmap that can lead us forward, and then act boldly on those objectives.

\section{The Promise of the University}

As with all institutions, universities are imperfect in many ways. However, I am drawn to the notion that the university is uniquely designed to fulfil a particular calling which, in its most elevated form, positions the institution to exercise a considerable act of bravery and humility: "to constantly test rather than impose the values it cherishes" (Giamatti 1990).

As I reflect on current-day examples of terrible abuses of public trust (first and foremost in my home country, the United States), the perversion of news sources, and the large-scale rejection of scientific evidence, let alone common sense, I am reminded of the wondrous potential that exists for universities to explore the limits of our knowledge and understanding in service to society - if given the appropriate freedom and relevant incentives to do so. I am convinced that the perpetuation and empowerment of universities are crucial for our collective well-being. Preserving and deepening our understanding of the past, enhancing our awareness of dynamics in the natural world, cultivating intellectual and technical talent across scores of fields and disciplines, critically questioning "the way things are," supporting the economic and social development of local communities, and helping us build a responsible future for the planet through technological and social innovation are among the key activities universities undertake around the world. We need these institutions, and we need organizations that support them, such as the IAU, to ensure our best chances for a better future.

\section{The Power of Associations}

There is no question that committed individuals can accomplish a great deal. However, collective action brings with it the possibility of greater resources, increased visibility, wider impact, and longer-term sustainability. Associations have long existed to align and elevate the interests and aspirations of individual actors in order to add value on a variety of levels. The pooling of resources, information, ideas, and good practices are known to offer important benefits to those who draw on these collective assets.

In today's 'networked world,' the value of shared resources is difficult to overestimate. This is clearly evident in the higher education sector, where all manner of networks, consortia, strategic partnerships and associations populate the landscape 
and provide immensely useful avenues for the advancement of both core business and special initiatives. Given the profoundly important role that universities can and should play in the world today, collective expressions of the needs and interests of the university community, and the stakeholders who may rely on or support the sector, must be carefully considered, artfully shaped, and intelligently amplified. Associations bring these collective expressions to life.

It is fascinating to consider that decades-old higher education associations - ranging from the 30+-year old European Association for International Education (EAIE), to the 100-year-old Institute of International Education (IIE) in the United States, to the 70-year-old IAU - are all entering new phases of intense and renewed relevance in socially and politically turbulent times. From my perspective, this aligns with the very clear watershed moments that surrounded the birth of these associations: IIE in the post-World War I era, IAU in the post-World War II years, and the EAIE during a period in the late 1980s of dynamic European integration, particularly in the higher education sector. These moments of intense change and new possibilities highlight the importance and utility of pooling insights and leveraging collective wisdom.

Indeed, associations give much-needed coherence and synergy among those who share a direction of travel but who are moving along somewhat erratically, or with limited coordination. We 'associate' with others to find fellowship, gain new insight, solve problems, and enjoy a shared sense of purpose. In a period of deep fragmentation within and across societies, associations offer a special kind of hope for collective action that serves a greater purpose. We need to draw on the strengths of our networks in the global higher education sector, embodied brilliantly by such associations as IAU and EAIE. We also need to ensure that these kinds of reinforcing and value-added avenues for collaboration and connection remain strong and viable at a time when both higher education and international engagement face enormous challenges.

\section{The Urgency of Internationalization}

The COVID-19 pandemic has illustrated two remarkable aspects of the current global reality. On the one hand, after decades of globalization - featuring the lowering of tariffs, the softening of borders, and the increasing international mobility of goods, services and people (notable among these, postsecondary students and faculty!) national borders around the world closed tight in a matter of days. It seems that the internationalization of our lives is, in reality, tenuous at best - at least when it comes to border controls. Meanwhile, the need to think internationally, and ideally globally, about the nature of this crisis and its eventual resolution, came quickly to the fore. Rapid development and deployment of a vaccine may be most achievable if researchers around the world pool their data and insights, and the spread of the disease - which recognizes no official borders - may be slowed if governments bring a coordinated approach to public health protocols. While the drastic reduction in international travel undoubtedly slowed the spread of the virus, the closing of avenues of collaboration will undermine our common objectives. 
International cooperation has been a hallmark of the IAU's work for seven decades and must continue to sit centre-stage as we aim to find our way out of this terrible international public health crisis and consider the future of our world beyond this moment. The work involved in advancing internationalization in higher education must be imbued with ever greater degrees of agility to adapt to changing circumstances, and, in all instances, with unwavering commitments to addressing inequity, serving the common good, and sustaining the natural environment. Focusing ever more intently on what international cooperation ultimately aims to achieve - in the context of life on an increasingly crowded, interconnected, fragile, and unequally resourced planet - sits at the heart of the matter. The International Association of Universities (IAU), its member institutions, many of its sister organizations, and the global higher education community at large - as values-driven organizations - are all on the right side of this argument. How best to enact these values fearlessly, effectively, and consistently remains the central issue moving forward.

Universities, associations, and internationalization: these actors and dynamics can make a measurable difference in a world facing enormous challenges on many fronts. Our collective future will be richer if we are able to offer the right kind of challenge and support to bring out the best that these actors and endeavours have to offer our societies: knowledge to guide us, fellowship to sustain us, and perspectives that value all humanity.

\section{Reference}

Giamatti, A.B. (1990). A Free and Ordered Space: The Real World of the University. New York: W. W. Norton \& Company.

Laura E. Rumbley $\mathrm{PhD}$, is Associate Director, Knowledge Development and Research at the European Association for International Education (EAIE), the Netherlands. Before joining the EAIE, she was Associate Director of the Boston College Center for International Higher Education (CIHE), and she previously served as deputy director of the Academic Cooperation Association (ACA) in Brussels. Laura is a co-editor of the Journal of Studies in International Education and serves on various international higher education publication and project boards. 
Open Access This chapter is licensed under the terms of the Creative Commons Attribution 4.0 International License (http://creativecommons.org/licenses/by/4.0/), which permits use, sharing, adaptation, distribution and reproduction in any medium or format, as long as you give appropriate credit to the original author(s) and the source, provide a link to the Creative Commons license and indicate if changes were made.

The images or other third party material in this chapter are included in the chapter's Creative Commons license, unless indicated otherwise in a credit line to the material. If material is not included in the chapter's Creative Commons license and your intended use is not permitted by statutory regulation or exceeds the permitted use, you will need to obtain permission directly from the copyright holder. 